\title{
The application of simultaneous paver liquid cement sprinkling system in the road construction of Yun-Mao Highway
}

\author{
Boqian $\mathrm{He}^{1^{*}}$ and $\mathrm{Ji} \mathrm{Xu}^{2}$ \\ ${ }^{1}$ Guangdong Guanyue Road Bridge Limited Company, Guangzhou, Guangdong Province, 511400, China \\ ${ }^{2}$ Poly Changda Engineering Co.Ltd., Guangzhou, Guangdong Province, 510620,China
}

\begin{abstract}
The simultaneous paver liquid cement sprinkling system is the combination of a conventional paver and a simultaneous liquid cement sprinkler. During operation, the cement sprinkler can be installed onto a paver with the use of connectors. When paving the stabilization aggregate mixture, this system sprinkles liquid cement on the working surface. This device can effectively solve the common quality issues such as the formation of cement isolation layer and road pollution, as a result of premature hardening of the pre-sprinkled liquid cement during road construction in high-temperature environments.
\end{abstract}

\section{Technology Background}

In the construction of highway inorganic binder stabilization layer, the binding of layers is usually achieved by sprinkling cement powder or liquid cement in advance, with the aim to strengthen the binding between stabilization layers. In previous construction work, liquid cement was sprinkled before the construction of the stabilization layers. During construction, the delivery truck moves on the road with sprinkled liquid cement to deliver materials to the paver, which leads to the adhering of liquid cement to the tyres of the truck. After the truck leaves, the liquid cement on the tyres can usually pollute other road surfaces that have been constructed. This also disturbs the liquid cement binding layer, causing relatively poor local binding. During construction under high temperature, the pre-sprinkled liquid cement can easily harden prematurely. This leads to not only a loss of the binding effect, but also the formation of an isolation layer, affecting the integrity of the structural layer and causing potential quality issues.

\section{Design Principle}

To address the drawback of the current technique, the aim of this device is to provide a simultaneous paver liquid cement sprinkling system, in order to solve the problems presented the technology background above [1]. The simultaneous paver liquid cement sprinkling system can sprinkle cement at the same time as the construction work on stabilization layer, ensuring the interlayer binding and reducing the issue of road pollution.

This device achieves the above aim with the following technical solution. The simultaneous paver liquid cement sprinkling system consists of the main body of the paver and a triangular supporting arm attached to the right side of the paver. The sprinkling components are installed on the right end of the triangular supporting arm, which is located on the right side of the paver. The sprinkling components include a supporting bottom plate, which is connected to the main body of the paver through the triangular supporting arm. The top of the supporting bottom plate is installed from front to back with a water tank, a cement holding plate and a cement mixing tank. The top of the supporting bottom plate is connected to the water inlet on top of the cement mixing tank via a water inlet pipe. The left side of the cement mixing tank is connected to a delivery pump via a pipe. The delivery pump is installed on top of the supporting bottom plate and is connected to a polygonal line-shaped slurry delivery pipe. The polygonal line-shaped slurry delivery pipe is fixed to the two sides of the main body of the paver, as well as below the pulley where the material funnel of the paver main body and the wheels of the material delivery truck are in touch. The portion of the polygonal line-shaped slurry delivery pipe on two sides of the paver main body is fixed with the slurry delivery pipe of the paver.

\section{Outcomes}

In the construction project of Yun-Mao highway, this device is used in the construction of cement stabilization layer in road construction [2]. It solved the common quality issues such as insufficient inter-layer binding, premature hardening of liquid cement and road pollution as a result of sprinkling liquid cement in advance [3]. The interlayer binding between cement stabilization layers is effectively strengthened and the overall performance of the road structural layer is improved [4].

In the simultaneous paver liquid cement sprinkling system, the supporting bottom plate is attached to the right side of the main body of the paver via a triangular supporting arm. This allows the simultaneous movement

\footnotetext{
${ }^{*}$ Corresponding author: 269661476@qq.com
} 
of the bottom plate with the main body of the paver. The bottom plate supports the water tank, cement holding plate, cement mixing tank and the pump. The bottom plate carries the water for cement mixing. The cement holding plate carries cements in bags. Liquid cement is produced by stirring the cement and a proper amount of water in the cement mixing tank. The liquid cement is then delivered by the pump to the polygonal line-shaped slurry delivery pipe, outside the main body of the paver. The liquid cement is then injected by the nozzles in front of the polygonal line-shaped slurry delivery pipe. In the meantime, the paver operates and lays the cement stabilizing crushed rock aggregate on top of the liquid cement. Due to the simultaneous paving of cement stabilizing crushed rock aggregate and the liquid cement, the road surface is not sprinkled with liquid cement when the delivery truck moves on the road to supply the aggregate material to the paver. As a result, liquid cement would not adhere to the tyres of the delivery truck, and hence the pollution issue of the finished roads by liquid cement is avoided.

\section{Financial Benefit Analysis}

Taking the construction work of cement stabilizing crushed rock base layer in the TJ14 section of the Guangdong Yun-Mao Highway project as an example, the differences in equipment cost and labor cost between using the conventional manual liquid cement presprinkling technique and the simultaneous paver liquid cement sprinkling system (under the condition that the material consumption and material delivery cost stay constant) are shown below. The use of the conventional manual liquid cement pre-sprinkling technique requires a sprinkling vehicle ( $¥ 1000$ / machine shift), four assistant workers ( $¥ 200$ /person*working day); the use of the simultaneous paver liquid cement sprinkling system requires two assistant workers ( $¥$ 200/person*working day) and two sets of equipment at each construction site. Each set requires an one-off manufacturing cost of Y 50000. With the TJ14 section of the Guangdong YunMao Highway project as an example (12-month construction period, two construction sites), the comparison of the financial costs of the two techniques are shown in Table 1. From Table 1, the use of the simultaneous paver liquid cement sprinkling system can save around $¥ 610000$ of financial costs in the TJ14 section.

\section{Social Benefit Analysis}

Since the use of the simultaneous paver liquid cement sprinkling system can better achieve the sufficient binding between the stabilization layers, the formation of cement isolation layer due to the premature hardening of liquid cement is avoided. This also prevents the liquid cement layer being rolled, adhered to and disturbed by the material delivery truck. As a result, the construction quality of the overall road structural layer is guaranteed [5] and the potential quality issues during operation as well as the associated maintenance costs are reduced. Certain social benefits are achieved and in the meantime the technological development in this sector is promoted.

Table 1. Comparison of the financial costs of the two techniques.

$\begin{array}{ll}\text { Comparison of techniques } & \begin{array}{l}\text { Equipment and labor costs of liquid cement sprinkling in Total } \\ \text { the TJ14 section of Yun-Mao Highway }\end{array}\end{array}$
the TJ14 section of Yun-Mao Highway

Manual liquid cement presprinkling technique
2 construction sites*12 months*24 machine shift/month* $\quad ¥ 1036800$
$¥ 1000$ /machine shift= $¥ 576000$

2 construction sites*4 workers*24 working day/month*

$¥ 200 /$ person* ${ }^{*}$ working day* 12 months $=¥ 460800$

Simultaneous paver liquid cement sprinkling system

2 construction sites $* 2$ sets*one-off $¥ 50000 /$ machine $=$ $¥ 200000$

2 construction sites*2 workers*24 working day/month*

$¥ 200 /$ person*working day* 12 months $=¥ 230400$
$¥ 430040$ 


\section{Supplementary Images of the Structure}

(a).
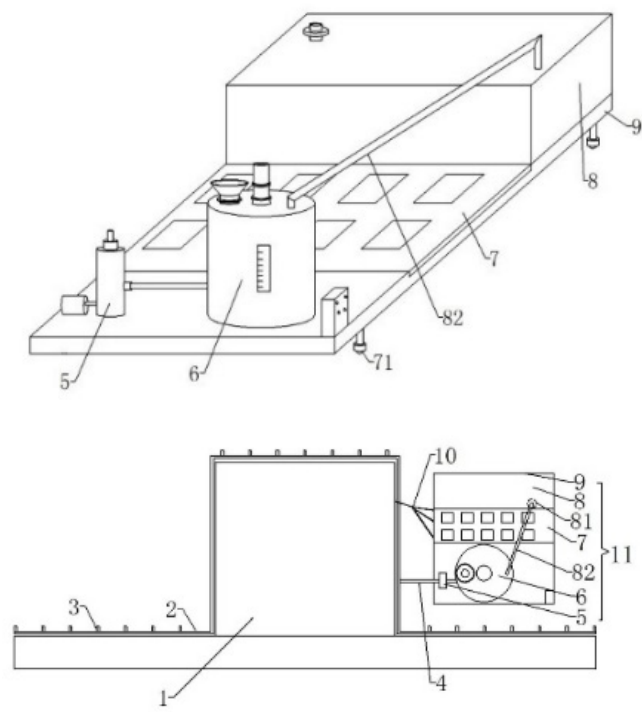

(b).

Figure 1. Layout of (a) the operating platform and (b) the overall structure.

In the supplementary image, each of the labelled components is shown below:

1-main body of paver,2-polygonal line-shaped slurry delivery pipe,3-liquid cement nozzle,4-slurry delivery pipe,5-delivery pump,6-cement mixing tank,7-cement holding plate, 8 -water tank,9-supporting bottom plate,10triangular supporting arm,11-sprinkling components,12-
U-shaped pipe,22-soft copper tube,23-L-shaped fixed plate,24-connecting tube,71-universal wheel,81-water pump,82-water inlet pipe.

\section{Photos of Construction on the Scene}

(a).
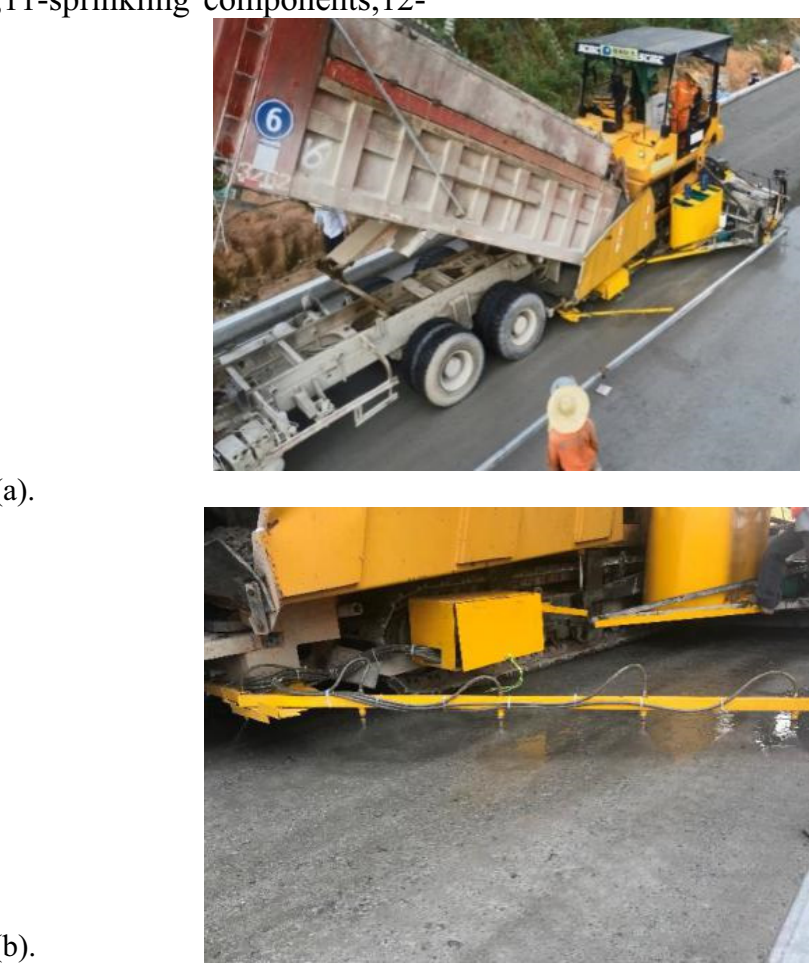

Figure 2. (a) Paving construction scene and (b) the sprinkled liquid cement. 


\section{Acknowledgements}

The authors would like to acknowledge the Guangdong Yun-Mao Highway Limited Company, Guangdong Guanyue Road Bridge Limited Company and Poly Changda Engineering Co.Ltd. for their assistance.

\section{References}

1. National Intellectual Property Administration of the People's Republic of China. Guangdong Guanyue Road Bridge Limited Company. Certificate of Utility Model Patent of the Simultaneous Paver Liquid cement Sprinkling System (Certificate number: 11226057) (2020). https://02291451.11315.com/ac/p/1597197220162.

2. Ministry of Transport of the People's Republic of China. Recommended Industry Standards. JTG/T F20-2015 Construction Guidelines for Highway Base and Subbase (2015). http://xxgk.mot.gov.cn/2020/jigou/glj/202006/t2020 0623_3312274.html.

3. H. Sun, J. Zhao, Z. Qin, The design on mixing ratio of liquid cement for cement stabilization inter-layer sprinkling and its construction technique. The World of Building Materials 6 (2015). https://kns.cnki.net/kcms/detail/detail.aspx?dbcode= CJFD\&dbname $=$ CJFDLAST2016\& filename $=\mathrm{GWJ}$ $\mathrm{K} 201506006 \& \mathrm{v}=3 \mathrm{HB} 1 \mathrm{aBc} 7 \mathrm{yoY} 3 \mathrm{AZ} 1 \mathrm{sQoFmo} 7 \mathrm{yz}$ Vdpvcfg\%25mmd2FAZTkJj6K12Y7iJnHNcW\%25 mmd2FH1LlbGpL\%25mmd2Flpr

4. G. Kuang, The key technique for road surface cement stabilization layer construction. Road Transportation $\begin{array}{llll}\text { Technologies } & \text { (Applied) } & 4 & \text { (2019). }\end{array}$ https://kns.cnki.net/kcms/detail/detail.aspx?dbcode= CJFD\&dbname $=$ CJFDLAST2019\& filename $=\mathrm{GLJJ} 2$ 01904024\&v=PM9JqgXaXmHxro0ZhKy4fTKeCpt kaMEKCQBpgEofI0wvpe $\% 25 \mathrm{mmd} 2 \mathrm{~B} \% 25 \mathrm{mmd} 2 \mathrm{~F} 8$ TK1V1RWriZaG\%25mmd2FhE

5. Q. Fu, Quality control measures for crushed stone foundation construction in cement stabilization layer of road engineering. Transport World 27 (2020). https://kns.cnki.net/kcms/detail/detail.aspx?dbcode= CJFD\&dbname $=$ CJFDLAST2020\& filename $=$ JTSJ2 $02027029 \& v=v 214 M R D$ thytiNVz5nA16dIqxZ54uh OPRn\%25mmd2F32BAk5q46ueN1GkTr\%25mmd2 F7BccUFFxeyML 